\title{
A future for nuclear energy: pebble bed reactors
}

\author{
Andrew C. Kadak \\ Department of Nuclear Engineering 24-202, \\ Massachusetts Institute of Technology, \\ 77 Massachusetts Avenue, \\ Cambridge, MA 02139, USA \\ E-mail: kadak@MIT.EDU
}

\begin{abstract}
Pebble Bed Reactors could allow nuclear plants to support the goal of reducing global climate change in an energy hungry world. They are small, modular, inherently safe, use a demonstrated nuclear technology and can be competitive with fossil fuels. Pebble bed reactors are helium cooled reactors that use small tennis ball size fuel balls consisting of only 9 grams of uranium per pebble to provide a low power density reactor. The low power density and large graphite core provide inherent safety features such that the peak temperature reached even under the complete loss of coolant accident without any active emergency core cooling system is significantly below the temperature that the fuel melts. This feature should enhance public confidence in this nuclear technology. With advanced modularity principles, it is expected that this type of design and assembly could lower the cost of new nuclear plants removing a major impediment to deployment.
\end{abstract}

Keywords: pebble bed reactor; safety; economics; modularity; PBMR.

Reference to this paper should be made as follows: Kadak, A.C. (2005) 'A future for nuclear energy: pebble bed reactors', Int. J. Critical Infrastructures, Vol. 1, No. 4, pp.330-345.

Biographical notes: Dr. Kadak is presently Professor of the Practice in the Nuclear Engineering Department at MIT. He is the former President and CEO of Yankee Atomic Electric Company, a nuclear plant operator and provider of nuclear engineering and environmental services to nuclear plants. His current research interests are the conceptual design and development of advanced reactors and space nuclear power.

\section{Introduction}

One of the major challenges of the reintroduction of nuclear energy into the world energy mix is the development of a nuclear power plant that is competitive with other energy alternatives, such as natural gas, oil or coal. The environmental imperative of nuclear energy is obvious. No greenhouse gases emitted, small amounts of fuel required and small quantities of waste to be disposed of. Unfortunately, the capital costs of new nuclear plants are quite large relative to the fossil alternatives. Despite the fact that nuclear energy's operating costs in terms of operations and maintenance and, most importantly, fuel are much lower than fossil alternatives, the barrier of high initial investment is a significant one for utilities around the world. 
In order to deal with this challenge, the students and faculty at the MIT started the redevelopment of a technology that was originally invented and tested in Germany in the 1970s and 1980s. A pebble bed research and demonstration reactor operated at the Juelich Research Institute for over 22 years, demonstrating the soundness of the technology. Unfortunately, Germany has abandoned its nuclear programme for all practical purposes, but it was recently picked up at the MIT, in China and South Africa, quite independently. In China, there is an operating $10 \mathrm{MW}$ thermal, $4 \mathrm{MW}$ electric pebble bed reactor (Figure 1) that is being used as a research demonstration facility to lay the groundwork for a full scale demonstration plant that has recently been agreed to by a Chinese utility and the Tsinghua University's Institute of Nuclear Energy Technology. In South Africa, the pebble bed modular reactor (PBMR) has been under design and development for approximately ten years. The PBMR is currently under licence review and final design in South Africa, which currently has a start of construction date in 2007, with a commercial operation date in 2010. At the MIT, which began revisiting pebble technology in 1998 under the auspices of a student design project, the challenge posed to the students was to see if they could address the economic obstacle of new nuclear plants. After a careful review of the existing challenges for nuclear power and the expectations of the public relative to new plants, the students chose the pebble bed reactor as their technology of choice for the following reasons:

- It was naturally safe, i.e., it is not physically possible to cause a meltdown and no credible accidents would result in significant fuel damage.

- It was small. The students judged that 100-200 megawatts electric would be the size necessary for international deployment of this technology. While the students recognised the potential advantage of economies of scale, they concluded that economies of production, namely smaller units with less investment and shorter construction time built out in modules to meet demand, would be the most economically attractive to many nations and utility companies.

- Online refuelling was judged to be a major advantage, avoiding long refuelling shutdowns. Pebble bed reactors are continually refuelled by removing used fuel and adding fresh fuel pebbles during operation.

- They decided that an intermediate cycle in which the main nuclear reactor coolant helium is separated from the power conversion system was the best approach. This decision, made very early, is presently one of the major attractive features of the design since it gives tremendous flexibility in the design of the mechanical power conversion system and is 'hydrogen ready'. The intermediate heat exchanger transfers the heat of the helium coolant in the reactor to another helium system to produce either electric power or very high grade heat to hydrogen conversion plants. The intermediate cycle is the cycle chosen for the next generation nuclear plant being planned for construction and demonstration for the Idaho National Laboratory as part of the advanced nuclear-hydrogen initiative.

- The students also recognised the importance of public acceptance and chose the pebble bed reactor largely because it was a new technology from the standpoint of public awareness. Its inherent safety features could be easily explained without reliance on complicated human action or emergency core cooling systems. 
Figure 1 Chinese high temperature reactor (HTR-10)

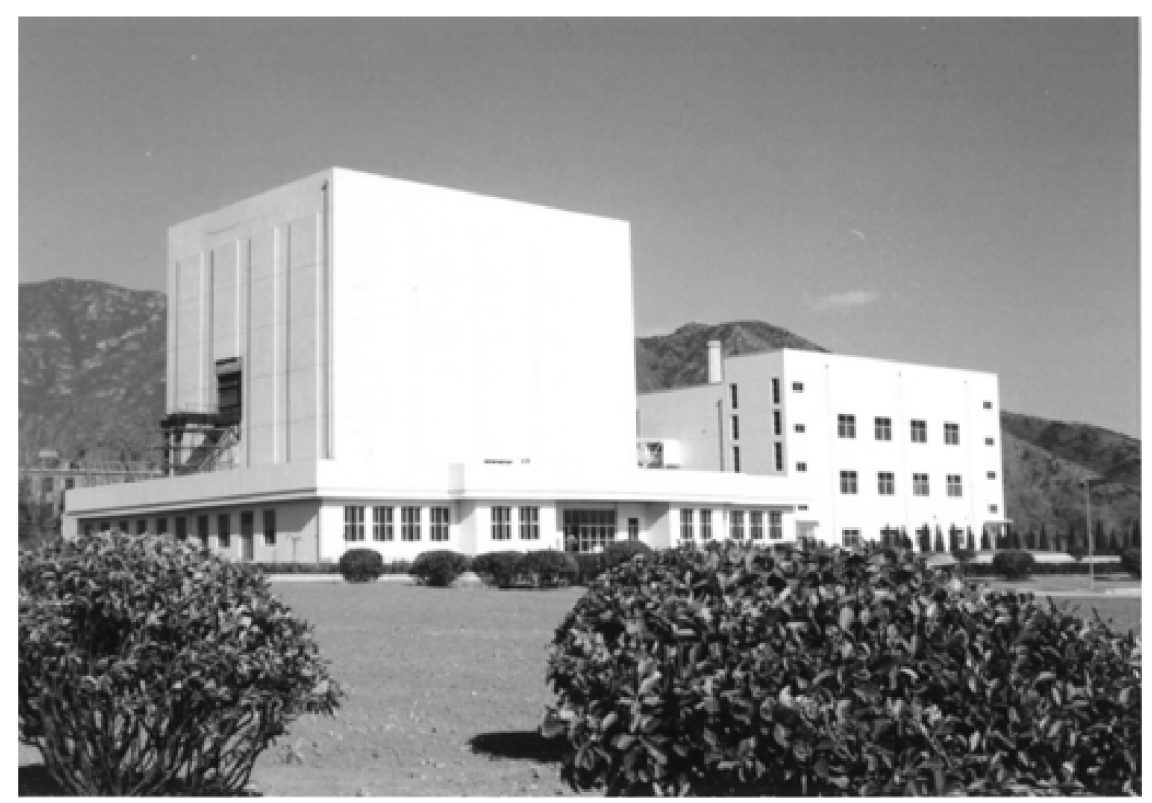

\subsection{The environmental imperative}

People in the world are seriously debating the existence and implications of increasing greenhouse gases in our environment due to the burning of these same fossil fuels. While the environmental ministers of nations from around the world seek to find ways to meet the 1992 Kyoto Accord, which calls for reductions in $\mathrm{CO}_{2}$ and other greenhouse gases to $10 \%$ below 1990 levels, the reality more than ten years later is that $\mathrm{CO}_{2}$ emissions have not decreased but increased by over $10 \%$. As most know, one of the key advantages of nuclear energy is that it is essentially a greenhouse gas emission free technology. Yet the environmental ministers of the Kyoto accord nations voted to specifically exclude nuclear energy as part of the plant to address the global warming problem. This position, if maintained, is clearly irrational and not science based since, in the USA, nuclear energy provided over $69 \%$ of the emission free electric power generation far exceeding that of hydroelectric power of $30 \%$ solar and other renewables provide the rest $(\sim 1 \%)$.

\subsection{The economic imperative}

For many years, nuclear energy, while arguably a non- $\mathrm{CO}_{2}$ emitting energy source, has been judged to be unacceptable for reasons of safety, unstable regulatory climate, a lack of a waste disposal solution and more recently economics. In recent years, however, the nuclear industry has made a remarkable turnaround. While a number of older plants have been shutdown for largely economic reasons, the 104 operating nuclear plants performance has increased to the point that as an overall fleet, its capacity factor was over $90 \%$ in 2002. This means that these plants were operating full power for over $90 \%$ of the year. This performance improvement in the last ten years is essentially the same as building 23 new 1,000 MWe plants in that time period based on historical performance 
averages. In addition, all safety statistics, as measured by the Nuclear Regulatory Commission, have shown dramatic improvements as well. The Three Mile Island accident occurred over 25 years ago. Yet the image of nuclear energy as an unsafe technology still persists. However, the record is quite the opposite.

There has been no new order for a new nuclear plant in the USA since the mid-1970s. The reason for the lack of new orders was the high capital cost. When operating in a difficult regulatory environment, utility executives simply avoided new nuclear construction and went to the cheapest and fastest to bring online generation available, which was natural gas. Combined cycle gas plants were the generation source of choice for many years for those companies that needed to build plants.

Today, utility executives still do not have new nuclear plant construction in their future plans even though the regulatory regime has stabilised. Nuclear plants are performing extremely well. Safety issues have been addressed with few major issues emerging with the exception of international terrorism, which is forcing utilities to make costly upgrades to their security systems. Slow progress is being made to finally dispose of spent fuel at the Yucca Mountain. To address the inevitable problem of replacing existing generation, utilities have chosen to re-license existing plants from the current 40 years to 60 years. Many nuclear plants have applied and received Nuclear Regulatory Commission approval to do so. These extensions will allow utilities to continue to use these plants as long as they are economic and continue to be safely operated. Unfortunately, there is still no new order for new nuclear plants although US utilities are working on early site permitting to allow for new nuclear construction once the economics of these plants is established.

There are developments in three parts of the world that are aimed at changing that situation. The objective of these related efforts is to design, license and build a nuclear power plant that can compete with natural gas. The three projects started independently but reached the same conclusions - that small modular high temperature gas reactors that are naturally safe, can be built in two to three years and can compete in the electricity market. While the basic technology is over 20 years old, the application and concepts are quite new. The leader in this effort is ESKOM, the 5th largest utility in the world located in South Africa. China, through the Tsinghua University's Institute of Nuclear Energy Technology, has designed, built and is now operating a MWth thermal and 4 MWe research demonstration plant near Beijing. The third effort is being led by the Massachusetts Institute of Technology with support from the Idaho National Engineering and Environmental Laboratory.

The nuclear energy plant that all groups are developing is a modular 110-165 MWe high temperature pebble bed reactor using helium gas as a coolant and the gas for electric production using gas turbine technology. The fundamental concept of the reactor is that it takes advantage of the high temperature properties of helium, which permit thermal efficiencies upwards of 50\%. It utilises an online refuelling system that can yield capacity factors in the range of $95 \%$. Its modularity designs concepts, which allow for a 2-3 year construction period, with expansion capabilities to meet merchant plant or large utility demand projections.

Economic projections for the plant in South Africa indicate capital costs of between US\$800 and \$1,000 (pl. query) per kilowatt. Staffing levels for a 1,100 MWe, 10 unit module is about 85 and fuel costs at about 0.5 cents $/ \mathrm{kwhr}$ (pl. query). When all are combined, the total busbar cost of power ranges from 1.6 to 2 cents $/ \mathrm{kwhr}$. Very preliminary estimates in the USA for the MIT project show higher costs, but on a 
relative scale the numbers are well within the range of competitive prices with new combined cycle plants at 3.3 cents per kilowatt hour.

\section{What is a pebble bed reactor?}

Pebble bed reactors were developed in Germany over 20 years ago. At the Juelich Research Center, the AVR pebble bed research reactor rated at 40 MWth and $15 \mathrm{MWe}$ operated for 22 years demonstrating that this technology works. The reactor produced heat by passing helium gas through the reactor core consisting of uranium fuelled pebbles. A steam generator was used to generate electricity through a conventional steam electric plant. Germany also built a $300 \mathrm{MWe}$ version of the pebble bed reactor but it suffered some early mechanical and political problems that eventually led to its shutdown. In December 2000, the Institute of Nuclear Energy Technology of the Tsinghua University in Beijing, China, achieved first criticality of their 10 MWth pebble bed research reactor. In the Netherlands, the Petten Research Institute is developing pebble bed reactors for industrial applications in the range of $15 \mathrm{MWth}$. The attraction to this technology is its safety, simplicity in operation, modularity and economics.

Advances in basic reactor and helium gas turbine technology have produced a new version of the pebble bed reactor concepts. Instead of using less efficient steam cycles to produce electricity, new designs as going to direct or indirect cycle helium gas turbines to produce electricity. These designs have target thermal efficiencies in the range of $45 \%$ compared to $32 \%$ for steam cycles. By avoiding the use of high temperature water, all the difficulties associated with maintaining high temperature water systems are eliminated. The optimum size for a pebble bed was concluded to be about $250 \mathrm{MW}$ th thermal to allow for rapid and modular construction as well as maintaining its inherent safety features. These designs do not require expensive and complicated emergency core cooling systems since the core cannot melt. These advances have led the ESKOM and the MIT team to independently conclude that the modular pebble bed reactor can meet the safety and economic requirements for new generation. Currently, the South African design has been upgraded to $400 \mathrm{MWth}$ and $165 \mathrm{MWe}$ electric. It is in the final design stage with construction to begin in 2007 and commercial operation in 2010.

A pebble bed reactor is graphically illustrated in Figure 2. The reactor core contains approximately 360,000 uranium fuelled pebbles about the size of tennis balls. Each pebble contains about $9 \mathrm{gm}$ of low enriched uranium in 10,000-15,000 (depending on the design) tiny grains of sand-like microsphere coated particles each with its own a hard silicon carbide shell. These microspheres are embedded in a graphite matrix material as shown in Figure 3. The unique feature of pebble bed reactors is the online refuelling capability in which the pebbles are recirculated with checks on integrity and consumption of uranium. This system allows new fuel to be inserted during operation and used fuel to be discharged and stored on site for the life of the plant. It is projected that each pebble will pass through the reactor 6-10 times before discharge in a three year period on average. With online refuelling, capability outages are determined by turbine generator maintenance, which is expected to require six year maintenance intervals. 
Figure 2 Schematic of a pebble bed reactor

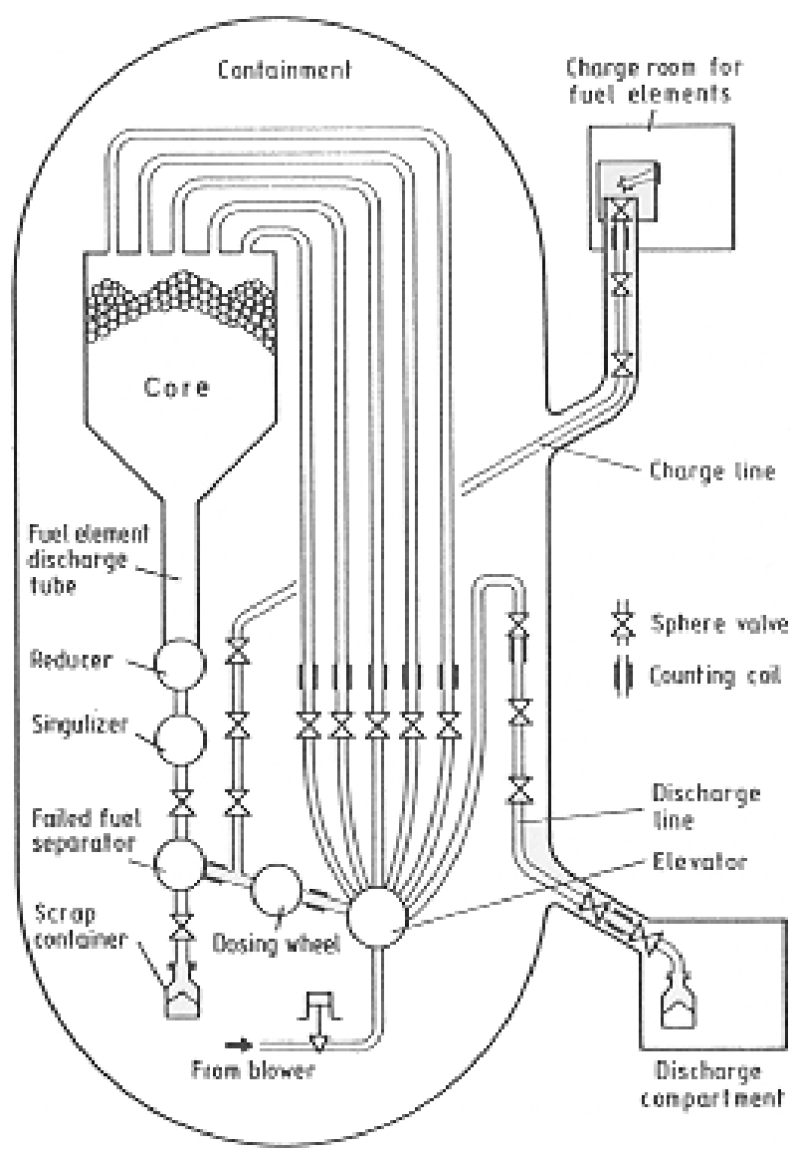

Figure 3 Fuel pebble and microsphere

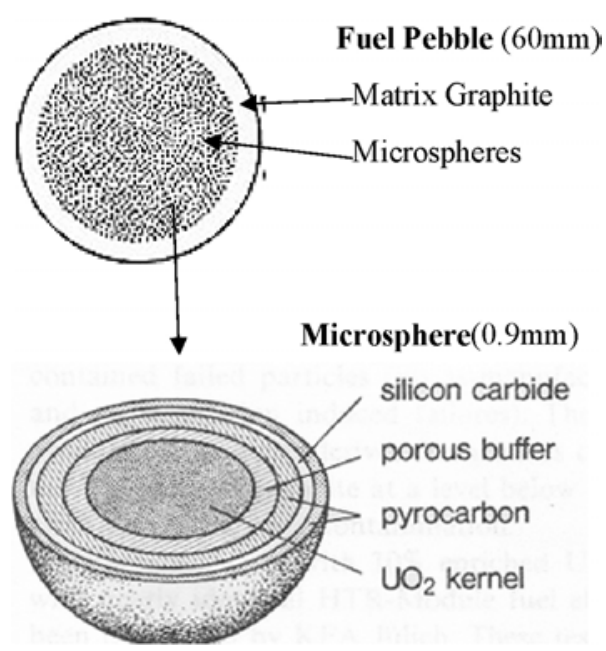


The key reactor specifications for the modular pebble bed reactor as being developed by the MIT are shown in Table 1.

Table 1 Nuclear specifications for the MIT pebble bed reactor

\begin{tabular}{ll}
\hline Thermal power & $250 \mathrm{MW}-120 \mathrm{MWe}$ \\
Target thermal efficiency & $45 \%$ \\
Core height & $10.0 \mathrm{~m}$ \\
Core diameter & $3.5 \mathrm{~m}$ \\
Pressure vessel height & $16 \mathrm{~m}$ \\
Pressure vessel radius & $5.6 \mathrm{~m}$ \\
Number of fuel pebbles & 360,000 \\
Microspheres/fuel pebble & 11,000 \\
Fuel & $\mathrm{UO} 2$ \\
Fuel pebble diameter & $60 \mathrm{~mm}$ \\
Fuel pebble enrichment & $8 \%$ \\
Uranium mass/fuel pebble & $7 \mathrm{~g}$ \\
Coolant & $\mathrm{Helium}$ \\
Helium mass flow rate & $120 \mathrm{~kg} / \mathrm{s}(100 \%$ power $)$ \\
Helium entry/exit temperatures & $520 / 900 \mathrm{C}$ \\
Helium pressure & $80 \mathrm{bar}$ \\
Mean power density & $3.54 \mathrm{MW} / \mathrm{m}^{3}$ \\
Number of control rods & 6 \\
\hline
\end{tabular}

The pebbles are located in the reactor core structure whose cross-section is shown in Figure 4. The internals are made of carbon blocks, which act as a reflector and structural support for the pebble bed. One of the new features of pebble bed core design is to include a central graphite reflector either in the form of a dynamic central column of unfuelled graphite pebbles or a solid structure as is being considered by the South Africans. The purpose of this column is to allow for higher power levels while still maintaining the effectiveness of external control rods in the outer reflector. The MIT design still uses the dynamic central column due to its flexibility in design. A picture of the Chinese internal carbon structure is shown in Figure 5. Please note the pebbles in the bottom of the central portion of the graphite discharge section. 
Figure 4 Reactor cross section

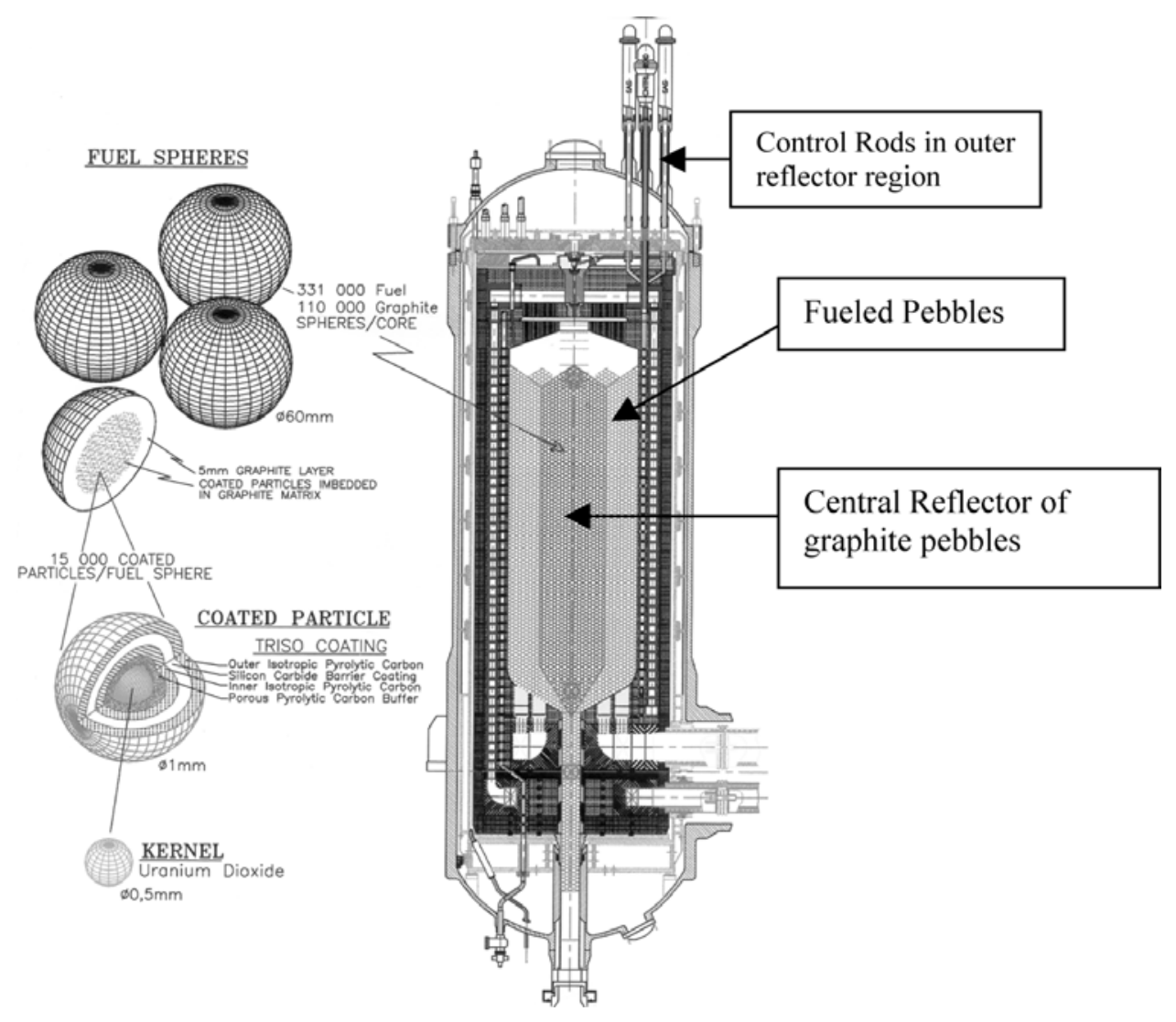

Figure 5 Lower core internals HTR-10 China

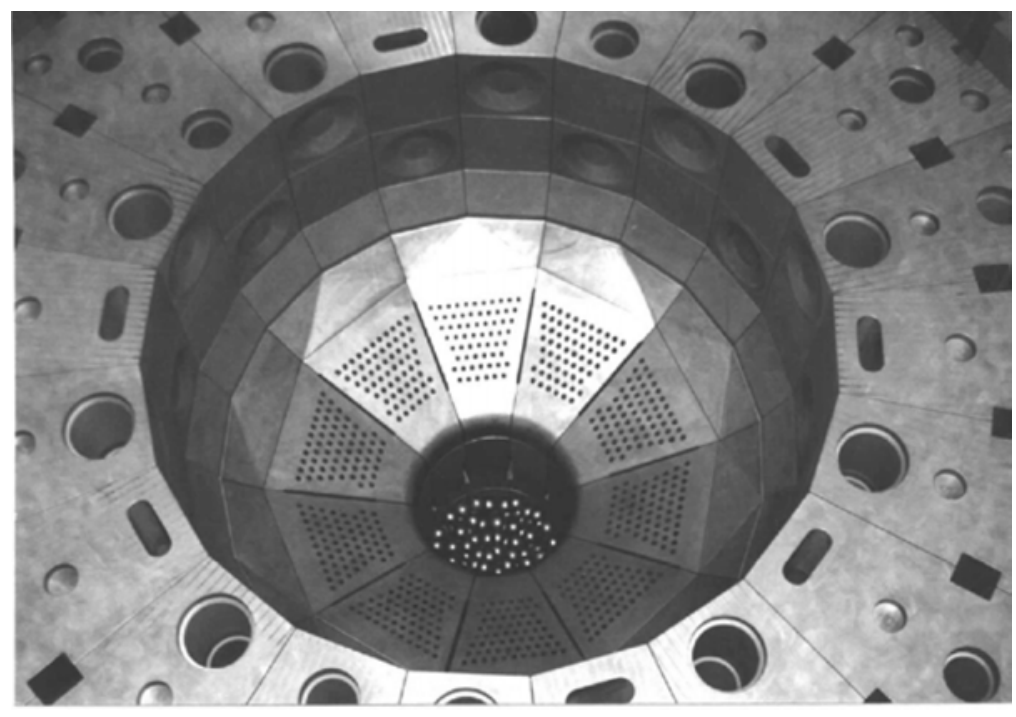




\section{Balance of plant}

There are two options under development

- a direct cycle helium gas turbine system being developed by the ESKOM

- $\quad$ an indirect helium to helium intermediate heat exchanger gas turbine system being developed by the MIT.

Each has its advantages and disadvantages with the key being the bottom line cost as measured in cents per kilowatt-hour. The direct cycle plant configuration of the ESKOM PBMR design is shown in Figure 6. In this design there are essentially two large vessels - one containing the reactor and the other the balance of plant. The indirect cycle being developed by the MIT is shown in Figure 7. Conceptually, the MIT turbo machinery module could be built in a factory and truck shipped to the site for simple assembly. If this modularity strategy is realised, it would revolutionise how nuclear energy plants are built. The MIT schematic of the thermo-hydraulic system for its indirect cycle is shown in Figure 8. The basis for this preliminary design is that all components were sized to be available at present. The intermediate heat exchangers operating at $900^{\circ} \mathrm{C}$ need to be developed; however, the Japanese High Temperature Test Reactor reached core outlet temperatures of $950^{\circ} \mathrm{C}$. The HTTR has several types of heat exchangers as part of the design. Advanced designs are being developed to simplify the plant even further.

Figure 6 PBMR direct cycle schematic

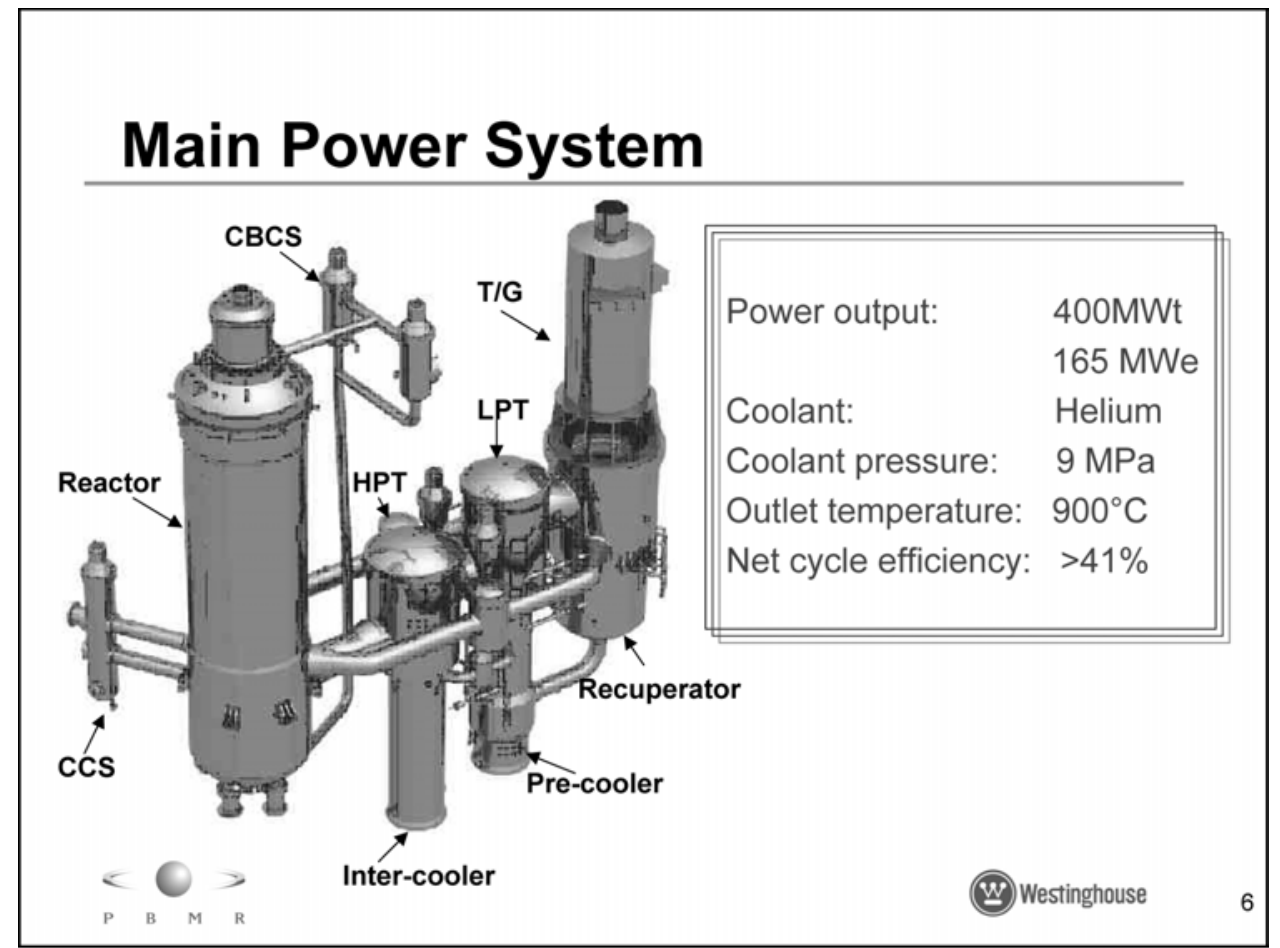


Figure 7 MIT pebble bed reactor layout

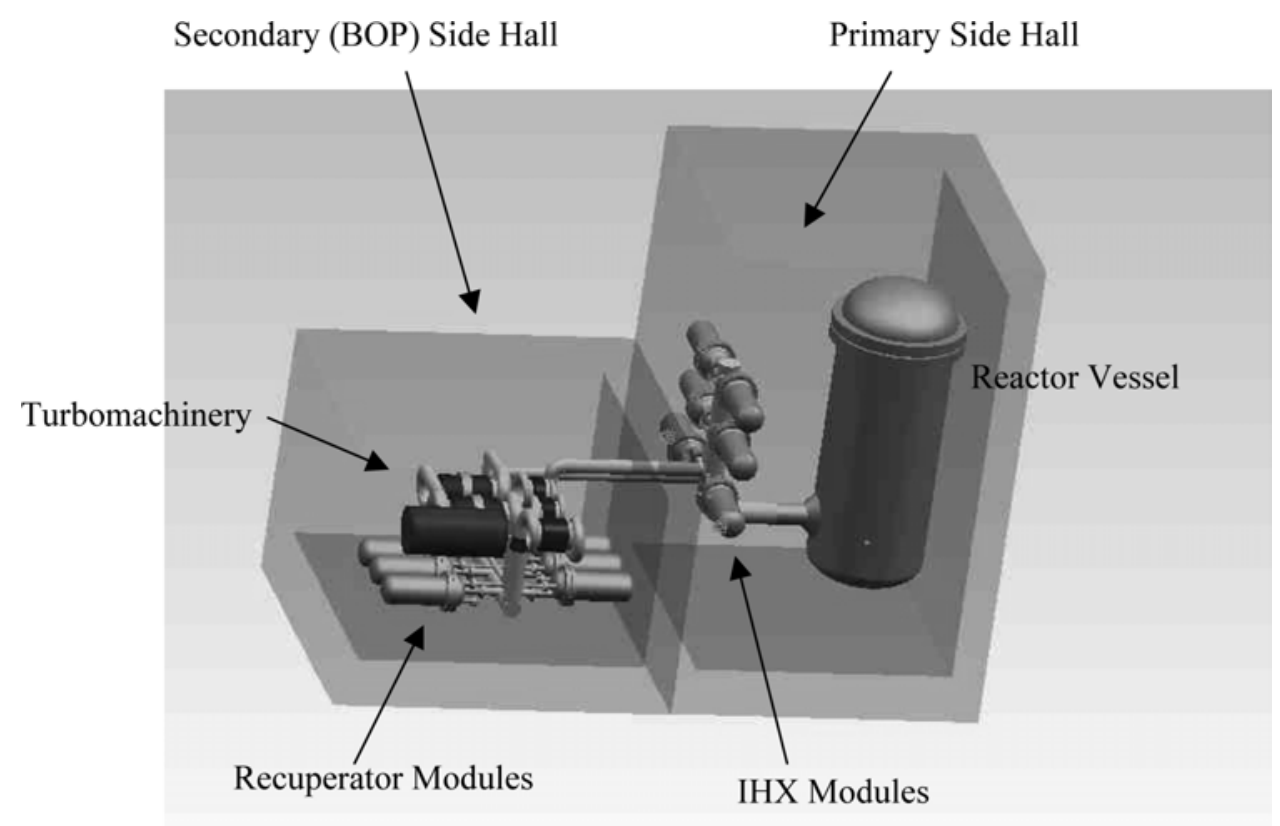

NOTE: Space-frames and ancillary components not shown for clarity

Figure 8 Schematic of MIT pebble bed thermal hydraulic system

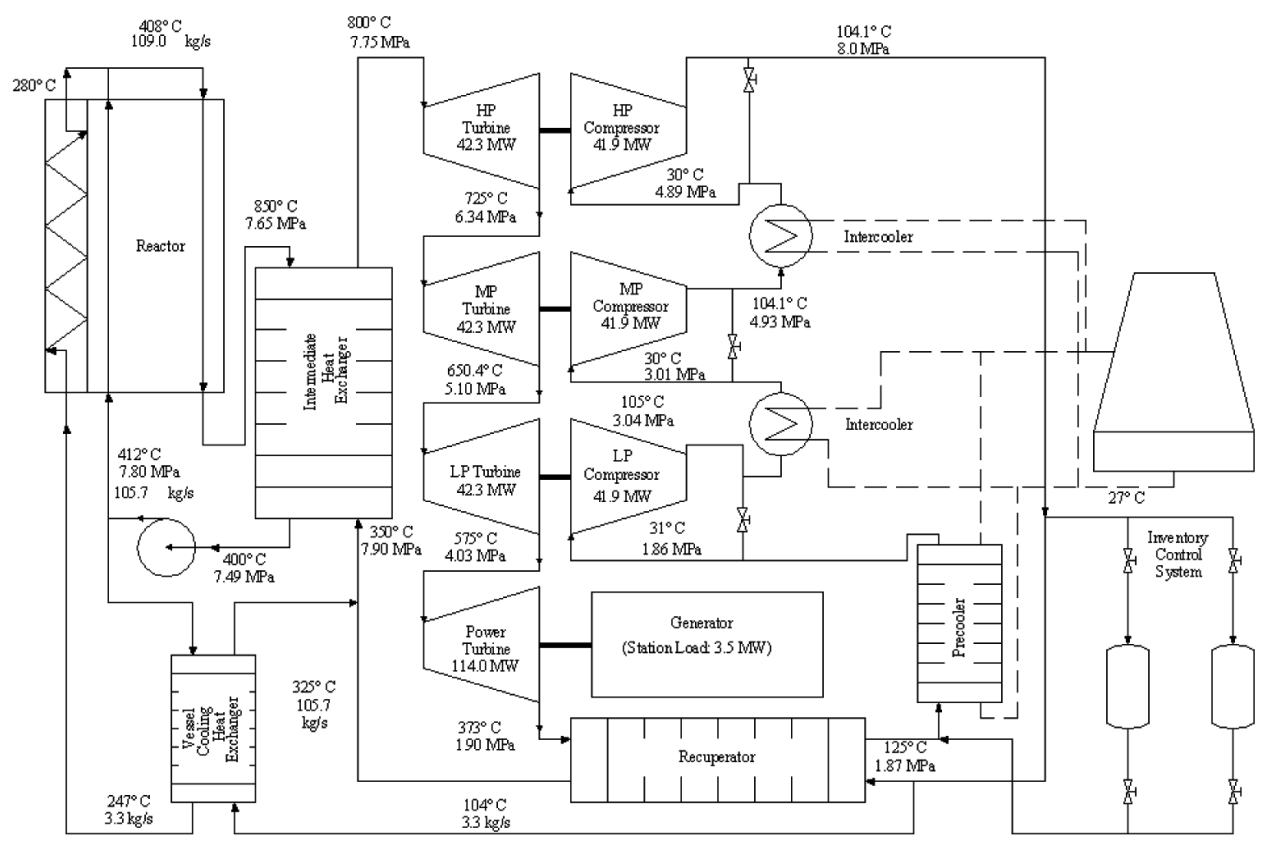


Should there be a need for a 1,100 MWe plant, 10 modules could be built at the same site. The concept calls for a single control room operating all ten units through an advanced control system employing many of the multi-plant lessons of modern gas fired power plants in terms on modularity and automatic operation. Construction plans and schedules were developed to refine the cost estimates and schedule expectations. The preliminary schedule call for getting the first unit on line in slightly over two years with additional modules coming on line every three months. A unique feature of this modularity approach is that it allows one to generate income during construction as opposed to only paying interest during construction.

\section{Modularity}

The future of new nuclear power plant construction will depend in large part on the ability of designers to reduce capital costs and maintenance costs. One of the methods proposed is to enhance the modularity of designs in which the basic plant is built in a factory in modules and shipped to the site for assembly. The value of this approach is that it improves overall quality, reduces site field work and rework, and speeds the construction of the plant further reducing the time to operation. The advantage true modularity provides is that it takes advantage of the economies of production, not necessarily relying on the economies of scale to reduce costs. The other advantage of modularity is that it can reduce maintenance costs and down time since the modules, if properly designed, allow for a replacement rather than online repair strategy.

The MIT Pebble Bed project is developing a conceptual design of a 250 MWth - 120 MWe Modular Pebble Bed Reactor (MPBR) using an indirect helium to helium heat exchanger gas turbine cycle power plant. The basic design configuration is shown in Figure 1.

\section{Modularity principles in design}

The MPBR project is highly dependent on the ability to package the reactor, its intermediate heat exchanger (IHX), and the remaining balance of plant in such a way to allow the MPBR plant to be transported via low cost means (truck or train as opposed to barge), easily assembled with minimal tooling and re-working, and operated in a small footprint commensurate with conventional power plants. Based on this dependency, the following requirements and assumptions can be made. The modularity principles are the primary design constraint on the design since it was felt that with a highly modular plant, the economics will be much more favourable allowing this technology to compete against economies of scale.

All components other than the reactor vessel and its associated mechanical support systems must be transportable by heavy lift tractor/trailer truck. Given that heavy lift trucks are used to transport the BOP components to the plant location, the following limitations must be met. First, the maximum dimensions of any one module are 8 " wide, 12 " tall, and up to $60^{\prime \prime}$ long. Second, the maximum weight of a single module must be less than $\sim 200,000 \mathrm{lb}$. Finally, the modules must be contained in a steel space frame to support the components within and to align those components with the components in 
other modules. The assembly on site of the modules must be limited to stacking the space frames to align the various flanges and bolting the piping together.

The latest revision of the MPBR plant layout is based on using existing demonstrated helium component technology. The overall system is a four shaft (one low speed power shaft driving a generator and three separate turbo compressor sets) system. The intermediate heat exchanger (IHX) consists of six small modules each with its own containment vessel. This was done to limit the weight of each module to within the $200 \mathrm{klb}$ truck limit. Additionally, by splitting the IHX up into smaller modules, if there is damage or failure to a part of the IHX, the smaller module can be removed and replaced. The recuperator is split up into six modules like the IHX. This enables each recuperator module to be closely located to a corresponding IHX module, limiting the amount of piping required between the two. The new proposed layout is shown in Figure 9.

Figure 9 New proposed layout of MIT pebble bed reactor

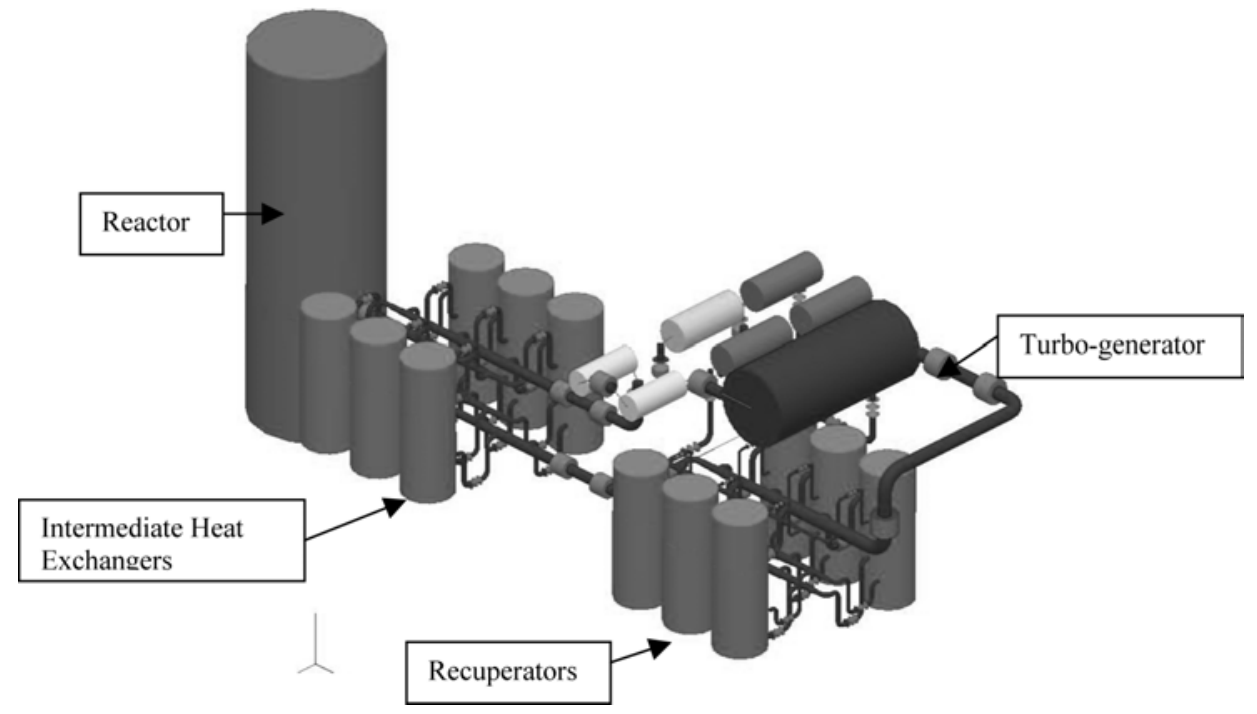

This layout seeks to maximise the modularity of the design by concentrating manifolds and plumbing in individual modules, while restricting each module to a single type of component (keeping turbomachinery in separate modules from heat exchangers whenever possible to minimise parasitic effects during maintenance). While this type-specific module isolation increases the total number of modules in the system, it limits the amount of functioning components that have to be removed during replacement of a single component.

This layout also simplifies construction of the plant, as the only large machinery needed to emplace the modules is a crane to emplace the top-level modules. Given the low lift height and overhead clearance needed to emplace these modules, such a crane could be limited to a hydraulic lift carriage, deliverable by truck, which would grasp each module, lift it to the correct height, and slide it onto rails built into the lower modules. Using this type of assembly, the amount of site preparation for the BOP part of the facility is minimal (a suitable pad type foundation with the proper load bearing specifications) and the on site tooling and machinery requirements is minimal (lift carriage, stud tensioner and flange assembly tools). 
Overall, this layout requires the use of 27 modules (not including command and control or power processing), each of which is truck transportable (Figure 10 - sample space frame shipping module). Shown in Figure 11 is the MIT modular pebble bed plant showing the major elements of the space frame modules.

Figure 10 Sample space frame shipping module

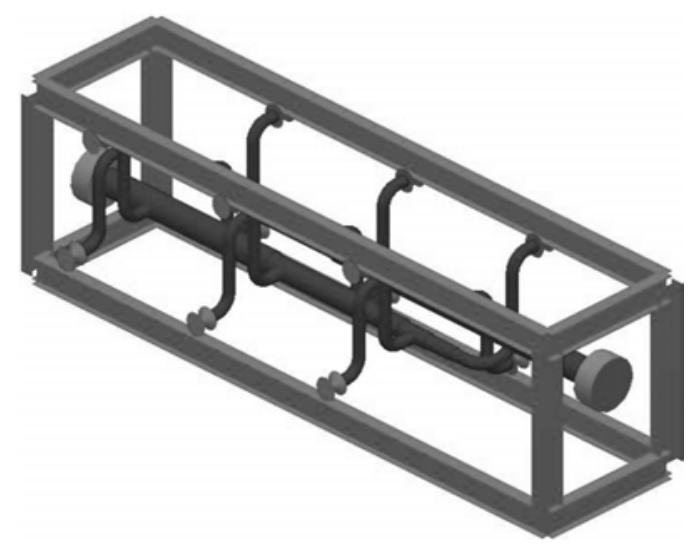

Figure 11 MIT pebble bed module plant

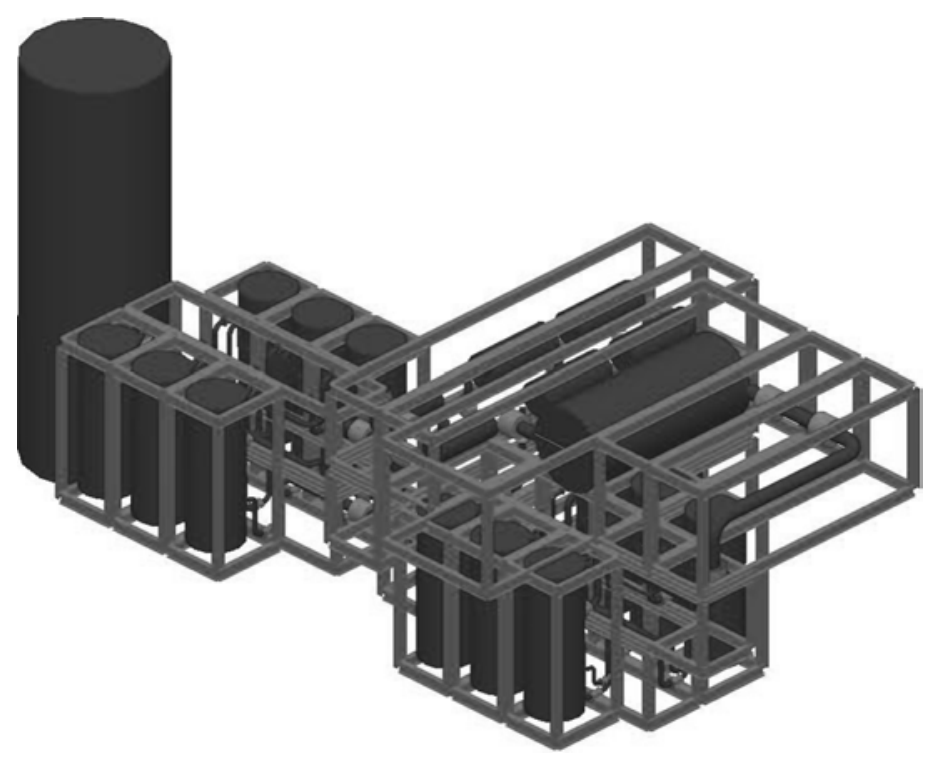

The balance of plant fits in a footprint roughly $80 \times 70 \mathrm{ft}$, a comparable size to $100 \mathrm{MWe}$ gas turbine facilities, and far smaller than conventional nuclear plants. With reactor vessel, such a plant could be easily made to fit within a $125 \times 80 \mathrm{ft}$ footprint, for a power density of roughly $10 \mathrm{~kW} / \mathrm{ft}^{2}$. For a conventional $1 \mathrm{GWe}$ plant, this power density would require a facility footprint of $\sim 100,000 \mathrm{ft}^{2}$. Given that conventional reactor containment buildings (not including the turbine shed and control facilities) consume nearly 40,000 $\mathrm{ft}^{2}$ on their own, this power density is equal to, if not greater than, conventional facilities, including advanced gas turbine systems. 


\section{The safety case}

The basis for the safety of pebble bed reactors is founded on two principles. The first is the very low power density of the reactor, which means that the amount of energy and heat produced is volumetrically low and that there are natural mechanisms such as conductive and radiative heat transfer that will remove the heat even if no convective core cooling is provided. This is significant since the temperature that is reached in a complete loss of coolant accident is far below the fuel damage threshold temperature and it takes about 70-80 hours to reach the peak temperature. Hence, the conclusion that fuel damage will not occur is valid and that certainly the core will not melt. This is supported by tests and analyses performed in Germany, Japan, China, South Africa and the USA.

The second principle is that the silicon carbide, which forms the tiny containment for each of the 10,000-15,000 coated fuel particles in a pebble, needs to be of sufficient quality so that it can retain the fission products. In tests performed to date on fuel reliability, it has been shown that microspheres can be routinely manufactured with initial defects of less than 1 in 10,000. In safety analyses, it is assumed therefore that 1 in 10,000 of these microspheres has a defect that would release the fission products into the coolant. Since the amount of fuel in each particle is very small, only $0.0007 \mathrm{gm}$, that even with this assumption and under accident conditions, the release from the core would be so low that no offsite emergency response would be required. In essence, it is recognised that the fuel cannot be made perfectly but the plant is still safe because it has natural safety features that prevent fuel damage. Manufacturing fuel quality is a key factor in the safety of high temperature gas reactors.

The other safety issue that needs to be addressed with all graphite reactors is that of air ingress. When at high temperatures, oxygen reacts with carbon to form $\mathrm{CO}$ and $\mathrm{CO}_{2}$. This oxidation and corrosion of the graphite is both an exothermic and endothermic reaction depending upon the conditions. Analyses and tests in Germany have shown that it is very difficult to 'burn' the graphite in the traditional sense, but it can be corroded and consumed. Some have made references to Chernobyl as an example of the problems with graphite reactors. Fortunately, however, the pebble design is radically different than the Chernobyl design in that the pebble bed does not contain water (steam explosions), nor zirconium that burns in air at high temperature and that the pebble bed reactor cannot reach the temperatures for melting fuel - all of which fuelled the Chernobyl fire.

The key issues for the pebble bed reactor are the amount of air available to the core from the reactor cavity, the resistance of the pebble bed to natural circulation flow, and whether a chimney can form to allow a flow of air into the core. Tests and analyses have shown that at these temperatures, graphite is oxidised and consumed but the conditions required for 'burning' are not obtainable - e.g., temperatures on the order of $3,000^{\circ} \mathrm{C}$. The corrosion process is more of a diffusion process. The MIT is now performing confirmatory analyses to understand the fundamental behaviour of air flow into a pebble bed reactor under the assumption of a major break in the circulating pipes or vessels.

\section{Economics}

No matter what the environmental, public health, safety and energy security advantages that nuclear energy may offer, if the product is not competitive, it will not be used. 
The MIT team used a comparative analysis of energy alternatives that was performed in 1992 by the Nuclear Energy Institute. The results of this comparative analysis for capital costs for a 10 unit modular plant show that the base plant overnight construction cost was US\$ 1.65 billion. Applying a contingency of $23 \%$ and an overall cost of money of $9.47 \%$, total capital cost estimate was US $\$ 2.3$ billion or about US $\$ 2,000 / \mathrm{kw}$ installed. On a per unit module, for a 110 MWe plant, the capital cost is estimated to be about US\$ 200 million. This estimate is approximately double that of the PBMR proposed by the ESKOM.

If construction costs were all that mattered, the pebble bed reactor would clearly not be economic compared to natural gas plants. However, when one includes the fuel and operating and maintenance costs since the pebble bed plant requires far fewer staff than conventional reactors due to their simplicity, the total cost of power estimated to be 3.3 cents per kilowatt hour was well within the competitive range for new natural gas plants.

\section{Financing strategy}

The financial community is justifiably skittish about nuclear investments due to the huge right offs that were required for the latest generation of nuclear plants. The beauty of this small modular plant is the initial investment for a module may range from US\$ 100 to US\$ 200 million dollars. This is not an astronomical amount of money. Also, the plant should be producing electricity within two and a half years, a fairly short time to be nervous about getting a return. These two factors should provide sufficient confidence to make the required investments as opposed to the billions and six years to see similar generation and returns for conventional light water reactor plants.

\section{Nuclear waste disposal}

The lack of a final repository for used nuclear fuel has been cited by some as a major obstacle to the building of new nuclear plants. While the need for a permanent waste disposal facility is real for existing plants and future plants, the progress being made in the USA and in other parts of the world in actually siting a number of these facilities is encouraging. Worldwide, scientific organisations, such as the US National Academy of Sciences, support geological disposal of high-level nuclear waste. In the USA, studies of the Yucca Mountain repository site on the grounds of the former Nevada Nuclear Weapons Test site continue to show that this location is a good site for the burial of nuclear wastes for tens of thousands of years. In early 2005, the Department of Energy will file a formal licence application with the Nuclear Regulatory Commission to build the high-level waste repository at the Yucca Mountain. In Sweden and Finland, underground repository experimental facilities have gotten local community support to actually build a test facility. Some nations are looking to reprocessing and long term storage since they do not feel the urgent need to have a facility in operation since the quantity of spent fuel in storage today is still relatively small. One repository could store all the spent nuclear fuel from all this nation's operating nuclear reactors for their 40 year licensed lives. Under optimistic circumstances, a repository at the Yucca Mountain could be open by 2010 according to DOE. 


\section{Summary}

While pebble bed reactors are not the only new nuclear energy technology being considered for the future, this technology is arguably the most advanced in terms of interest and development. The USA has chosen high temperature gas reactors as their technology of choice to power the future hydrogen economy in an emission free way. Pebble bed reactors offer the potential for meeting the needs of high energy efficiency, safety and economy if the concepts proposed in this paper are successfully implemented. South Africa and China are committed to developing pebble bed technology. Thus, pebble bed reactors offer a future for nuclear energy in combating global climate change in an affordable technology that has been demonstrated to work.

\section{Acknowledgments}

Professor Ronald Ballinger and the many students at MIT working on the pebble bed reactor project. The author also wishes to thank the Idaho National Engineering and Environmental Laboratory for early support of this project.

\section{Bibliography}

AVR (1990) AVR - Experimental High Temperature Reactor: 21 Years of Successful Operation for a Future Energy Technology, Association of German Engineers (VDI), The Society for Energy Technologies, Dusseldorf.

Evaluation of the Gas Turbine Helium Reactor (1993) DOE-HTGR-90380, December.

Kadak, A.C. and Berte, M.V. (2001) 'Modularity in design of the MIT pebble bed reactor', American Nuclear Society Meeting, November, Reno, Nevada.

Knief, R.A. (1992) Nuclear Engineering, Theory and Technology of Commercial Nuclear Power, 2nd ed., Hemisphere Publishing Corp., Taylor \& Francis, Washington, DC.

Melese, G. and Katz, R. (1984) Thermal and Flow Design of Helium Cooled Reactors, American Nuclear Society, Chicago, Illinois, ISBN: 0-89448-027-8.

MIT Nuclear Engineering Department (2005) Web site: web.mit.edu/pebble-bed/.

Nuclear Energy Institute. (1992) Advanced Design Nuclear Power Plants: Competitive, Economic Electricity.

Wang, C. (2003) Design, Analysis and Optimization of the Power Conversion System for the Modular Pebble Bed Reactor System, MIT Nuclear Engineering Department, PhD Thesis, 31 August.

Zhai, T., Kadak, A.C. and No, H.C. (2004) LOCA and Air Ingress Accident Analysis of a Pebble Bed Reactor, MIT Center for Advanced Nuclear Energy Systems, MIT-ANP-TR-102, March. 